\title{
Article \\ Comparison of the Efficiency of Two Types of Heat Exchangers with Parallel Plates Made of Varied Materials
}

\author{
Krzysztof Grysa (D), Artur Maciąg *(D) and Artur Ściana \\ Faculty of Management and Computer Modelling, Kielce University of Technology, 25314 Kielce, Poland; \\ grysa@tu.kielce.pl (K.G.); asciana@tu.kielce.pl (A.Ś.) \\ * Correspondence: maciag@tu.kielce.pl
}

Citation: Grysa, K.; Maciag, A.;

Ściana, A. Comparison of the

Efficiency of Two Types of Heat

Exchangers with Parallel Plates Made of Varied Materials. Energies 2021, 14, 8562. https://doi.org/10.3390/ en14248562

Academic Editors: Alessia Arteconi and Gianpiero Colangelo

Received: 7 November 2021

Accepted: 17 December 2021

Published: 19 December 2021

Publisher's Note: MDPI stays neutral with regard to jurisdictional claims in published maps and institutional affiliations.

Copyright: (C) 2021 by the authors. Licensee MDPI, Basel, Switzerland. This article is an open access article distributed under the terms and conditions of the Creative Commons Attribution (CC BY) license (https:// creativecommons.org/licenses/by/ $4.0 /)$.

\begin{abstract}
The paper discusses two mathematical models for the air flow through a plate heat exchanger with parallel plates. The first exhausts the used air and then supplies the fresh air. The second exhausts the used air above the plate and simultaneously supplies fresh air under it (counterflow exchanger). In both cases, the exhaust air heat is used to heat the supply air. The purpose of the research is to verify which exchanger uses the exhaust air heat more efficiently. The method of the Trefftz function was used to determine approximate solutions of the analysed problems. The results obtained for $1.2 \mathrm{~mm}$ thick steel, aluminium, and copper plates and for external winter, summer, and spring-autumn temperatures are discussed. The results indicate that steel is the best material for a plate heat exchanger, and the counter-flow exchanger is more efficient of the two. Thanks to the use of thin steel plates and the reduction of the air exchange time to a few minutes, cheap and efficient counter-flow exchangers can be obtained.
\end{abstract}

Keywords: heat transfer; heat exchanger; recuperator; Trefftz method

\section{Introduction}

A recuperator is a device used, among others, for supplying and extracting air from rooms as part of ventilation systems with heat recovery (recuperation systems). Connected to a properly executed ventilation system, it recovers heat (energy) from air, reducing the building's energy demand. The most important part of any recuperator, which determines heat recovery parameters, is the heat exchanger located centrally in the recuperator. There are many recuperator types, including those discussed in monographs [1,2] and presented on numerous websites, e.g., [3]. The exhaust air flows in the heat exchanger without mixing with the supply air. Energy is exchanged between the air fluxes. It enables the recovery of heat or cold (depending on the season). Numerous publications discussing heat exchanger types are known.

The paper discusses plate heat exchangers. A heat exchanger of this type is composed of many metal plates, and heat is transferred by the liquids flowing through them. The exchanger, made mainly of weather-resistant aluminium, deserves particular attention due to its unique design, which ensures the highest known efficiency, with a $100 \%$ share of fresh air. When one of the exchanger's sections takes heat from the exhaust air, the other gives off the stored heat to the cold supply air.

Another important feature is frost resistance. In the vertical positions, the upper part is cold, and the bottom part is warm. Condensate drops fall down to the warmer part, from where they are routed to the sewerage system. This direction of the condensate flow excludes the possibility of condensate getting into the cold part, preventing it from freezing. The main advantage is undoubtedly self-cleaning, which is ensured by a two-way air flow. For this reason, the effectiveness of two types of exchangers was analysed in order to optimise the design parameters.

Plate heat exchangers are among the most efficient heat transfer devices. However, the main limitation of plate heat exchangers is the fact that they can only be used in a 
relatively low pressure and temperature, [4]. Therefore, only heat exchangers operating under a small temperature difference (up to $50-60^{\circ} \mathrm{C}$ ) between the room from which the air is extracted and the outside area will be considered.

In a parallel flow exchanger, the air can be exchanged in two ways: (a) first, used air is exhausted from the room; then, fresh air is supplied from outside, or (b) used air is exhausted from the room, and at the same time, fresh air is supplied (counter-flow exchanger). In both cases, the heat collected during air exhaust is released by the panel to the fresh air supplied from the outside.

The literature does not focus on modelling the heat flow itself through a heat exchanger with parallel plates. In a number of studies, a model and a computational grid were developed to simulate a heat exchanger, and then fluid dynamics (CFD) computation software was launched. When assembling the heat exchanger, complicated and irregular narrow channels were created. For example, in [5] and [6], the authors dealt with heat exchangers and their different geometries. In [7], the authors presented a comparison of various grids for a plate heat exchanger modelled by a tetrahedral mesh. The influence of oblique waves on the heat transfer surface was investigated in [8]. Heat transfer in a channel with parallel plates was studied in [9] using Dissipative Particle Dynamics with energy conservation (eDPD). In [10], the design of a new plate heat exchanger and its cost were compared to heat exchangers available on the market. The production of heat exchangers (the medium is a liquid) with the use of 3D printing was discussed in [11]. The heat transfer was modelled by the Boltzmann mesh method. In the report [12], the application of a quasi 1-D code (Phyton) for the design of heat exchangers was described. The heat transfer was modelled by the balance of thermal energy and by empirical heat transfer correlations. A series of quasi-counter-flow parallel membrane channels was used for the construction of an air dryer in [13]. In addition, in [14], a numerical model simulating the operation of a drying system based on a parallel membrane system was considered.

Heat flow and transfer in a recuperative air-to-air counter-flow heat exchanger was studied numerically in [15]. The results therein indicate that the lowest possible material thickness is crucial for developing the most effective recuperative air-to-air counter-flow heat exchanger with high efficiency and low-pressure losses, the properties of the material itself being irrelevant.

The authors of [16] demonstrated that larger heat exchangers offer better efficiency and lower pressure drop with the same velocity.

A uniform air stream is very often applied as an inlet boundary condition of a heat exchanger in studies using computational fluid dynamics software. However, in actual applications, the inlet flow conditions are not uniform. The effect of non-uniformities on the thermal performance characterised in a wind tunnel for a commercially available plate water/air heat exchanger was investigated in [17].

To the authors' best knowledge, the problem of temperature distribution in time in the heat exchanger plate during the exhaust/supply air has not been the subject of any research yet.

This paper focuses on the heat distribution within an exchanger plate. As the plate is heated/cooled by air, the obtained plate temperatures at the air inlet and outlet correspond to the supply or exhaust air temperatures. The thermal conductivity equation based on Fourier's law was used to describe the heat flow through the plate. Boundary conditions describing the effect of air on the plate for both heat exchangers were formulated. For the sake of simplicity, the effects associated with air moisture or air contamination were omitted. By applying the Trefftz method, as described in Section 3, approximate solutions of heat conduction equations for both exchangers were obtained and discussed.

For the calculations, the assumed room temperature was $21^{\circ} \mathrm{C}$, while the outside temperatures were simulated as follows: frosty winter $\left(-19^{\circ} \mathrm{C}\right)$, early spring and later autumn $\left(+1^{\circ} \mathrm{C}\right)$, and hot summer $\left(+31^{\circ} \mathrm{C}\right)$. In [15], where a recuperative counter-current air-to-air plate heat exchanger was tested numerically using the Fluent software, it was found that the thinnest possible material is crucial for creating the most efficient air-to-air 
recuperative heat exchanger with low efficiency and low-pressure losses, and the properties of the material itself do not matter. The presented research confirmed the conclusions from the cited paper.

Mathematical description of the heat transfer issues for both types of exchangers is formulated in Section 2. In Section 3, the Trefftz method is discussed. An approximation of solutions for both exchangers using a linear combination of the Trefftz function (T-functions) is presented. Moreover, objective functionals are built. Minimization of the functionals leads to a system of algebraic equations for the coefficients of these linear combinations. Calculation results are presented in the form of graphs and tables in Section 4. In Section 5, results for both types of exchangers are compared, and further types of counter-flow steel plate exchangers are discussed. The conclusions summarize the results obtained.

\section{Formulation of Equations and Conditions for Both Tested Heat Exchangers}

A heat exchanger structure is made up of subsequent plate layers separated with successive air layers, which means it is a geometrically repeatable structure (the top and bottom plates are omitted). As a result, in the case of the "supply first from one side, then the other" operation, it is sufficient to take into consideration only one-half of the plate thickness with one-half of the air layer and assume the zeroing heat flux at the plate centreline with respect to $y$, (comp. Figure 1). In the case of supply from both sides (over the plate in one direction, and below in the opposite), the entire plate cross-section has to be considered, as shown in Figure 2. The shorter cross-sectional edges of the exchanger plate are hereinafter referred to as inner or left and outer or right.

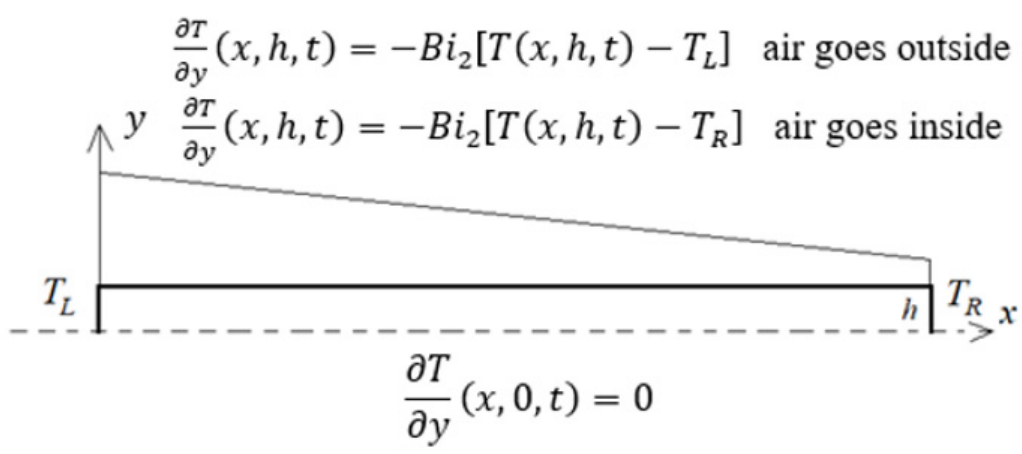

Figure 1. Heat exchanger plate cross-section with marked central surface and boundary conditions when air goes outside, variant (a1), or inside, variant (a2).

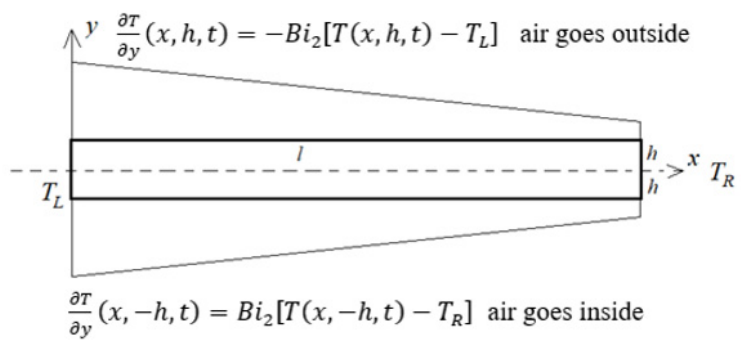

Figure 2. A counter-flow heat exchanger.

Disregarding the heat generated per unit of volume, we get an equation that will constitute a base for the computations, namely, [18,19],

$$
\nabla^{2} T-\frac{1}{a} \frac{\partial T}{\partial t}=0
$$


where $T(\mathrm{~K})$ describes temperature, $a=\frac{k}{\rho c}\left[\frac{m^{2}}{s}\right]$ is the so-called thermal diffusivity coefficient, $k(\mathrm{~W} /(\mathrm{mK}))$ is the thermal conductivity coefficient, $\rho\left(\mathrm{kg} / \mathrm{m}^{3}\right)$ stands for density, $c(\mathrm{~J} /(\mathrm{kg} \mathrm{K}))$ is specific heat, $t$ (s) stands for time, and $\nabla$ is the gradient operator.

The problem is two-dimensional. Spatial coordinates will be denoted as $x$ and $y$.

Heat exchange between the inner heat exchanger plates and the air supplied by the exchanger can follow two ways.

As mentioned in the Introduction, the heat exchange between the internal plates of the exchanger and the air supplied by the exchanger can take place in two ways: (a) first exhaust from the room, then supply from the outside; (b) simultaneous exhaust above the plate and supply air below it (counter-flow supply).

The air moves between the plates at a speed $v_{a}(\mathrm{~m} / \mathrm{s})$. After the time $\frac{l}{v_{a}},(l,(\mathrm{~m})$, being the length of the plate), it will reach the opposite end of the plate. The time is very short in relation to the total time of the supply (exhaust) operation; therefore, its potential impact on the thermal process is ignored.

The following dimensionless variables are introduced:

$$
\xi=\frac{x}{l}, \eta=\frac{y}{l}, F o=\frac{a t}{l^{2}} \tau-\text { Fouriernumber, } B i=\frac{\alpha l}{k}-\text { Biotnumber }
$$

where $\alpha\left[\frac{\mathrm{W}}{\mathrm{m}^{2} \mathrm{~K}}\right]$ is the heat transfer coefficient.

In both considered exchangers, the heat transfer coefficient $\alpha$ will be different for heat penetration on shorter edges $(\xi=0$ and $\xi=1)$, where it is assumed that air is immobile, and different on longer edges $\left(\eta= \pm \frac{h}{l}\right)$, where it moves at a velocity of $v_{a}$. The coefficient $\alpha$ is defined as falling within a range of $5-37 \frac{\mathrm{W}}{\mathrm{m}^{2} \mathrm{~K}}$, [20]. The relationship between $\alpha$ and laminar flow velocity, $v_{a}$, is determined by the equation [21,22].

$$
\alpha=\left\{\begin{array}{l}
5.8+4 v_{a} \text { for } v_{a}<5 \mathrm{~m} / \mathrm{s} \\
7.12 v_{a}^{2} \text { for } v_{a} \geq 5 \mathrm{~m} / \mathrm{s}
\end{array}\left[\frac{\mathrm{W}}{\mathrm{m}^{2} \mathrm{k}}\right]\right.
$$

The kinematic viscosity $v$ for air within a range of -20 to $30{ }^{\circ} \mathrm{C}$ changes in the range 11.8 to $16 \mathrm{~mm}^{2} / \mathrm{s}$. For the maximum air velocity, $v_{a}=4.5 \mathrm{~m} / \mathrm{s}$ (parallel to the longer cross-section edge), the Reynolds number $R e=v_{a} h / v$ will change within a range of 457 to 338. It means that laminar flow occurs between the plates, because for air flowing over the flat layer ( $h=0.0012 \mathrm{~m}$ - air duct height, adopted as plate thickness), the bottom critical Reynolds number is $R e_{k r}>10^{5}$ [23-25].

On the shorter plate edges, it is assumed that the air velocity is zero, i.e., the heat transfer coefficient is $\alpha_{1}=5.8 \mathrm{~W} /\left(\mathrm{m}^{2} \mathrm{~K}\right)$. On the longer edges $0<v_{a}<5 \mathrm{~m} / \mathrm{s}$ and $\alpha_{2}=5.8+4 v_{a} \mathrm{~W} /\left(\mathrm{m}^{2} \mathrm{~K}\right)$, (comp.(2.3), Biot numbers will be accordingly marked with $B i_{1}$ and $B i_{2}$.

Equation (1) in dimensionless coordinates takes the form

$$
\nabla^{2} T-\frac{\partial T}{\partial \tau}=0,0<\xi<1,0<\eta<\frac{h}{l} \tau>0 .
$$

Initial and boundary conditions for variant (a) are presented below. A heat exchanger plate cross-section with marked central surface and boundary conditions when air is exhausted from the room, variant (a1), or from outside, variant (a2), is shown at Figure 1.

Variant (a1)

- Initial condition at air flow from $T_{L}$ to $T_{R}$

$$
\nabla^{2} T-\frac{\partial T}{\partial \tau}=0,0<\xi<1,0<\eta<\frac{h}{l}, \tau<0 .
$$

- Boundary conditions 


$$
\begin{gathered}
\nabla^{2} T-\frac{\partial T}{\partial \tau}=0,0<\xi<1,0<\eta<\frac{h}{l}, \tau<0 \\
\frac{\partial T}{\partial \eta}\left(\xi, \frac{h}{l}, \tau\right)=-B i_{2}\left[T\left(\xi, \frac{h}{l}, \tau\right)-T_{L}\right], 0<\xi<1,0<\tau<\tau_{\text {end }} \\
\frac{\partial T}{\partial \xi}(1, \eta, \tau)=-B i_{1}\left(T(1, \eta, \tau)-T_{R}\right), 0<\eta<\frac{h}{l}, 0<\tau<\tau_{\text {end }} .
\end{gathered}
$$

- Condition of symmetry

$$
\frac{\partial T}{\partial \eta}(\xi, 0, \tau)=0,0<\xi<1,0<\tau<\tau_{\text {end }} .
$$

Variant (a2)

- The initial condition is described by the final condition for the variant (a1):

$$
T_{a 2}(x, y, 0)=T_{a 1}\left(x, y, t_{\text {end }}\right)
$$

where $t_{\text {end }}$ is the end moment of the supply (exhaust) process, $T_{a 1}\left(x, y, t_{\text {end }}\right)$, stands for the end temperature in variant (a1), and $T_{a 2}(x, y, 0)$ is the initial temperature in the variant (a2);

- $\quad$ Equations (8) and (9) hold, and

$$
\begin{gathered}
\frac{\partial T}{\partial \xi}(0, \eta, \tau)=B i_{1}\left(T(0, \eta, \tau)-T_{L}\right), 0<\eta<\frac{h}{l}, 0<\tau<\tau_{\text {end }} \\
\frac{\partial T}{\partial \eta}\left(\xi, \frac{h}{l}, \tau\right)=-B i_{2}\left[T\left(\xi, \frac{h}{l}, \tau\right)-T_{R}\right], 0<\xi<1,0<\tau<\tau_{\text {end }} .
\end{gathered}
$$

Variant (b)—counter-flow exchanger (comp. Figure 2)

The initial condition takes the Equation (5). Boundary conditions are as follows:

$$
\begin{gathered}
\frac{\partial T}{\partial \xi}(0, \eta, \tau)=B i_{1}\left(T(0, \eta, \tau)-T_{L}\right),-\frac{h}{l}<\eta<\frac{h}{l}, 0<\tau<\tau_{\text {end }} \\
\frac{\partial T}{\partial \eta}\left(\xi, \frac{h}{l}, \tau\right)=-B i_{2}\left[T\left(\xi, \frac{h}{l}, \tau\right)-T_{L}\right], 0<\xi<1,0<\tau<\tau_{\text {end }} \\
\frac{\partial T}{\partial \xi}(1, \eta, \tau)=-B i_{1}\left(T(1, \eta, \tau)-T_{R}\right),-\frac{h}{l}<\eta<\frac{h}{l}, 0<\tau<\tau_{\text {end }} \\
\frac{\partial T}{\partial \eta}\left(\xi,-\frac{h}{l}, \tau\right)=B i_{2}\left[T\left(\xi,-\frac{h}{l}, \tau\right)-T_{R}\right], 0<\xi<1,0<\tau<\tau_{\text {end }} .
\end{gathered}
$$

\section{Solution Method}

\subsection{Trefftz Functions}

The Trefftz method, [26], will be used to solve the problem. Its essence is the solution approximation using a linear combination of Trefftz functions (T-functions), constructed for Equation (4). Each of the T-functions satisfies the equation for which it has been developed.

There are three known methods of deriving the T-functions; they are described in more detail in many monographs and papers, e.g., [27]. The authors of [28] proved that a T-function system for a linear partial differential equation constitutes a complete function system for this equation. The proof is based on expanding the solution into a Taylor series and appropriately replacing the time derivatives by spatial derivatives therein. It means that any solution to this equation can be presented using an infinite series of these functions with appropriate coefficients. A finite linear combination of T-functions can be used as 
a base to develop an approximate solution. Of course, the more T-functions are used to obtain an approximate solution, the more accurate the approximation will be.

$\mathrm{T}$-functions for a one-dimensional problem have the form

$$
v_{n}(x, t)=\sum_{k=0}^{[n / 2]} \frac{x^{n-2 k} t^{k}}{(n-2 k) ! k !} .
$$

$n=0,1, \ldots[x]=$ floor $(x)$ means the integer part of number $x$. Two-dimensional T-functions are obtained as products of the one-dimensional T-functions:

$$
g_{m}(x, y, t)=v_{n-k}(x, t) v_{k}(y, t)
$$

where $k \leq n$. The relationship between $m$ and $n, k$ can be expressed as follows:

$$
m(n, k)=\left\{\begin{array}{c}
m(0, k-1)+k+1 \text { when } n=0, k>0 \\
m(n-1, k)+n+k \text { when } n>0 \\
m(0,0)=0 .
\end{array}, n, k=0,1,2, \ldots ;\right.
$$

An approximate solution, $T_{M}^{a p}(\xi, \eta, \tau)$, expressed by dimensionless variables, Equation (2), takes the form

$$
T_{M}^{a p}(\xi, \eta, \tau)=\sum_{m=0}^{M} c_{m} g_{m}(\xi, \eta, \tau)=\sum_{m=0}^{M} c_{m} v_{n-k}(\xi, \tau) v_{k}(\eta, \tau)
$$

where $k \leq n$.

\subsection{Objective Functionals}

In order to determine the constants $\left\{c_{m}\right\}_{m=0,1, \ldots, M}$, the mean square approximation of meeting the boundary and initial conditions by the function $T_{M}^{a}(\xi, \eta, \tau)$ will be used. Individual conditions, Equations (5) to (16), will be used to develop functionals, $J^{a 1}, J^{a 2}$, and $J^{b}$, describing the inaccuracy of satisfying these conditions for each variant separately (so-called objective functionals). The minimization conditions for each functional will be used to derive an algebraic system of equations for $\left\{c_{m}\right\}_{m=0,1, \ldots, M}$.

$$
\begin{gathered}
J^{a 1}\left(\left\{c_{m}\right\}\right)=\int_{0}^{1} \int_{0}^{h / l}\left(T_{M}^{a p}(x, y, 0)-\left(T_{L}(1-x)+T_{R} x\right)\right)^{2} d x d y+ \\
\int_{0}^{\frac{h}{l}} \int_{0}^{\tau_{\text {end }}}\left[\left(\frac{\partial T_{M}^{a p}}{\partial x}(1, y, t)+B i_{1}\left(T_{M}^{a p}(1, y, t)-T_{R}\right)\right)^{2}+\left(T_{M}^{a p}(0, y, t)-T_{L}\right)^{2}\right] d t d y+ \\
\int_{0}^{1} \int_{0}^{\tau_{\text {end }}}\left(\frac{\partial T_{M}^{a p}}{\partial y}\left(x, \frac{h}{l}, t\right)+B i_{2}\left[T_{M}^{a p}\left(x, \frac{h}{l}, t\right)-T_{L}\right]\right)^{2} d t d x+\int_{0}^{1} \int_{0}^{\tau_{\text {end }}}\left(\frac{\partial T_{M}^{a p}}{\partial y}(x, 0, t)\right)^{2} d x d t \\
J^{a 2}\left(\left\{c_{m}\right\}\right)=\int_{0}^{1} \int_{0}^{h / l}\left(T_{M}^{a p}(x, y, 0)-T_{a 1}\left(x, y, \tau_{\text {end }}\right)\right)^{2} d x d y+ \\
\int_{0}^{\frac{h}{l}} \int_{0}^{\tau_{\text {end }}}\left[\left(\frac{\partial T_{M}^{a p}}{\partial x}(1, y, t)+B i_{1}\left(T_{M}^{a p}(1, y, t)-T_{R}\right)\right)^{2}+\left(\frac{\partial T_{M}^{a p}}{\partial x}(0, y, t)-B i_{1}\left(T_{M}^{a p}(0, y, t)-T_{L}\right)\right)^{2}\right] d t d y+ \\
\int_{0}^{1} \int_{0}^{\tau_{\text {end }}}\left(\frac{\partial T_{M}^{a p}}{\partial y}\left(x, \frac{h}{l}, t\right)+B i_{2}\left[T_{M}^{a p}\left(x, \frac{h}{l}, t\right)-T_{R}\right]\right)^{2} d t d x+\int_{0}^{1} \int_{0}^{\tau_{\text {end }}}\left(\frac{\partial T_{M}^{a p}}{\partial y}(x, 0, t)\right)^{2} d t d x
\end{gathered}
$$




$$
\begin{gathered}
J^{b}\left(\left\{c_{m}\right\}\right)=\int_{0}^{1} \int_{-\frac{h}{l}}^{\frac{h}{l}}\left(T_{M}^{a p}(x, y, 0)-\left(T_{L}(1-x)+T_{R} x\right)\right)^{2} d x d y+ \\
\int_{-\frac{h}{l}}^{\frac{h}{l}} \int_{0}^{\tau_{\text {end }}}\left\{\left(\frac{\partial T_{M}^{a p}}{\partial x}(0, y, t)-B i_{1}\left(T_{M}^{a p}(0, y, t)-T_{L}\right)\right)^{2}+\left(\frac{\partial T_{M}^{a p}}{\partial x}(1, y, t)+B i_{1}\left(T_{M}^{a p}(1, y, t)-T_{R}\right)\right)^{2}\right\} d t d y+ \\
\int_{0}^{1} \int_{0}^{\tau_{\text {end }}}\left\{\left(\frac{\partial T_{M}^{a p}}{\partial y}\left(x, \frac{h}{l}, t\right)+B i_{2}\left[T_{M}^{a p}\left(x, \frac{h}{l}, t\right)-T_{L}\right]\right)^{2}+\left(\frac{\partial T_{M}^{a p}}{\partial y}\left(x,-\frac{h}{l}, t\right)-B i_{2}\left[T_{M}^{a p}\left(x,-\frac{h}{l}, t\right)-T_{R}\right]\right)^{2}\right\} d t d x \\
J^{b}\left(\left\{c_{m}\right\}\right)=\int_{0}^{1} \int_{-\frac{h}{l}}^{\frac{h}{l}}\left(T_{M}^{a p}(x, y, 0)-\left(T_{L}(1-x)+T_{R} x\right)\right)^{2} d x d y+ \\
\int_{-\frac{h}{l}}^{\frac{h}{l}} \int_{0}^{\tau_{\text {end }}}\left\{\left(\frac{\partial T_{M}^{a p}}{\partial x}(0, y, t)-B i_{1}\left(T_{M}^{a p}(0, y, t)-T_{L}\right)\right)^{2}+\left(\frac{\partial T_{M}^{a p}}{\partial x}(1, y, t)+B i_{1}\left(T_{M}^{a p}(1, y, t)-T_{R}\right)\right)^{2}\right\} d t d y+ \\
\int_{0}^{1} \int_{0}^{\tau_{\text {end }}}\left\{\left(\frac{\partial T_{M}^{a p}}{\partial y}\left(x, \frac{h}{l}, t\right)+B i_{2}\left[T_{M}^{a p}\left(x, \frac{h}{l}, t\right)-T_{L}\right]\right)^{2}+\left(\frac{\partial T_{M}^{a p}}{\partial y}\left(x,-\frac{h}{l}, t\right)-B i_{2}\left[T_{M}^{a p}\left(x,-\frac{h}{l}, t\right)-T_{R}\right]\right)^{2}\right\} d t d x
\end{gathered}
$$

To achieve the best solution approximation, the objective functional should reach a minimum. A minimum condition for this functional is zeroing of all of its first derivatives with respect to the $c_{m}, m=0,1, \ldots, M$. Thus, the obtained equations form an algebraic system $M+1$ of linear equations with the $M+1$ unknowns. They will take the form

$$
\frac{\partial J\left(\left\{c_{m}\right\}\right)}{\partial c_{m}}=0, \quad m=0,1, \ldots, M
$$

The coefficients $c_{m}, m=0,1, \ldots, M$, as in Equation (20) are solutions to the system of Equation (25).

In order to check how many terms of a linear Equation (20) have to be included in the computations to obtain a sufficient result accuracy, the values of the air outlet

\begin{tabular}{|c|c|c|c|c|c|c|}
\hline Material & $\begin{array}{l}T_{R}, \\
{ }^{\circ} \mathrm{C}\end{array}$ & $\begin{array}{l}T\left(l, h, t_{\text {end }}\right), \\
{ }^{\circ} \mathrm{C}, M=45\end{array}$ & $\begin{array}{l}T\left(l, h, t_{\text {end }}\right), \\
{ }^{\circ} \mathrm{C}, M=55\end{array}$ & $\begin{array}{l}T\left(l, h, t_{\text {end }}\right), \\
{ }^{\circ} \mathrm{C}, M=66\end{array}$ & $\begin{array}{l}T\left(l, h, t_{\text {en } d}\right) \\
{ }^{\circ} \mathrm{C}, M=78\end{array}$ & $\begin{array}{l}T\left(l, h, t_{\text {end }}\right), \\
{ }^{\circ} \mathrm{C}, M=91\end{array}$ \\
\hline \multirow{3}{*}{$\begin{array}{c}\text { Steel, } \\
v_{a}=0.5\end{array}$} & -19 & -10.94 & -11.1 & -11.1 & -10.98 & -10.98 \\
\hline & 1 & 5.03 & 4.99 & 4.99 & 5.01 & 5.01 \\
\hline & 31 & 28.98 & 29 & 29 & 29 & 29 \\
\hline
\end{tabular}
temperature, i.e., $T_{M}^{a p}\left(l, h, t_{\text {end }}\right)$, were checked, in cases where $M=44,54,65,77$ and 90 (terms are numbered from zero). The tests adopted steel as the material, $t_{\text {end }}=600 \mathrm{~s}$ as the process time, and the $l$ and $h$ values as in Section 4.1. The results presented in Table 1 , calculated for three values of outside temperature $T_{R}$, exhibit slight differences on the second decimal place.

Table 1. Studies involving the number of linear combination (3.2) terms regarding computation accuracy.

The result of these considerations, combined with the observation that in each case, the time of calculations performed by the PC using the MAPLE program was of the order of a few minutes, finally allowed us to adopt the number of 66 T-functions, i.e., $M=65$.

\section{Computation Results}

The following data were adopted for the computations:

$T_{L}=21^{\circ} \mathrm{C}$ (room or inside temperature),

$T_{R}=-19{ }^{\circ} \mathrm{C}$ (outside temperature), $1{ }^{\circ} \mathrm{C}, 31^{\circ} \mathrm{C}$,

$l=1.2 \mathrm{~m}$ (plate section length),

$h=0.0006 \mathrm{~m}$ (plate section half height),

$v_{a}=0.5 \mathrm{~m} / \mathrm{s}$ and $4.5 \mathrm{~m} / \mathrm{s}$, 


$$
\begin{aligned}
& \alpha_{1}=5.8 \frac{\mathrm{W}}{\mathrm{m}^{2} \mathrm{~K}} \\
& \alpha_{2}=5.8+4 v_{a} \frac{\mathrm{W}}{\mathrm{m}^{2} \mathrm{~K}^{\prime}} \\
& t_{\text {end }}=300 \mathrm{~s} \\
& M=65 \text { (66 T-functions), }(n=0,1, \ldots, 10, k=0,1, \ldots<n, \text { respectively, comp. }
\end{aligned}
$$
Equation (19)).

Calculations were conducted for copper, aluminium, and steel. Their thermophysical data are presented in Table 2. The temperature of plate surface, $y=h$, was studied for $x \in(0, l)$ and $t \in\left(0 ; t_{\text {end }}\right)$.

Table 2. Plate material [29,30].

\begin{tabular}{cccccc}
\hline & $\rho\left[\mathrm{kg} / \mathbf{m}^{\mathbf{3}}\right]$ & $\begin{array}{c}c \\
{[\mathrm{~J} /(\mathbf{k g ~ K})]}\end{array}$ & $k[\mathbf{W} /(\mathbf{m K})]$ & $\begin{array}{c}a \cdot \mathbf{1 0}^{\mathbf{6}} \\
{\left[\mathbf{m}^{\mathbf{2}} / \mathbf{s}\right]}\end{array}$ & $\boldsymbol{\alpha}\left(\mathbf{W} /\left(\mathbf{m}^{\mathbf{2}} \mathbf{K}\right)\right)$ \\
\hline copper & 8933 & 385 & 386 & 112.2 & $5.8+4 v v_{a}<5$ \\
\hline aluminium & 2702 & 903 & 204 & 83.6 & $5.8+4 v v_{a}<5$ \\
\hline stainless steel & 7970 & 561 & 19.5 & 4.36 & $5.8+4 v v_{a}<5$ \\
\hline
\end{tabular}

\subsection{Results for Variant (a)}

For the temperature calculation in variants (a1) and (a2), the objective functionals $J^{a 1}$ and $J^{a 2}$ were used (cf. Equations (21) and (22)). First, the copper plate was considered. The temperature distribution for the case for $T_{R}=-19{ }^{\circ} \mathrm{C}, v_{a}=0.5 \mathrm{~m} / \mathrm{s}$ is presented in Figure 3 for time is given in seconds and distance in meters.

- for $T_{R}=-19^{\circ} \mathrm{C}, v_{a}=0.5 \mathrm{~m} / \mathrm{s}$

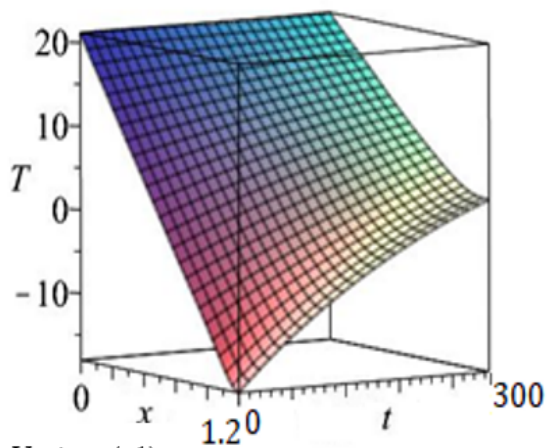

Variant (a1)
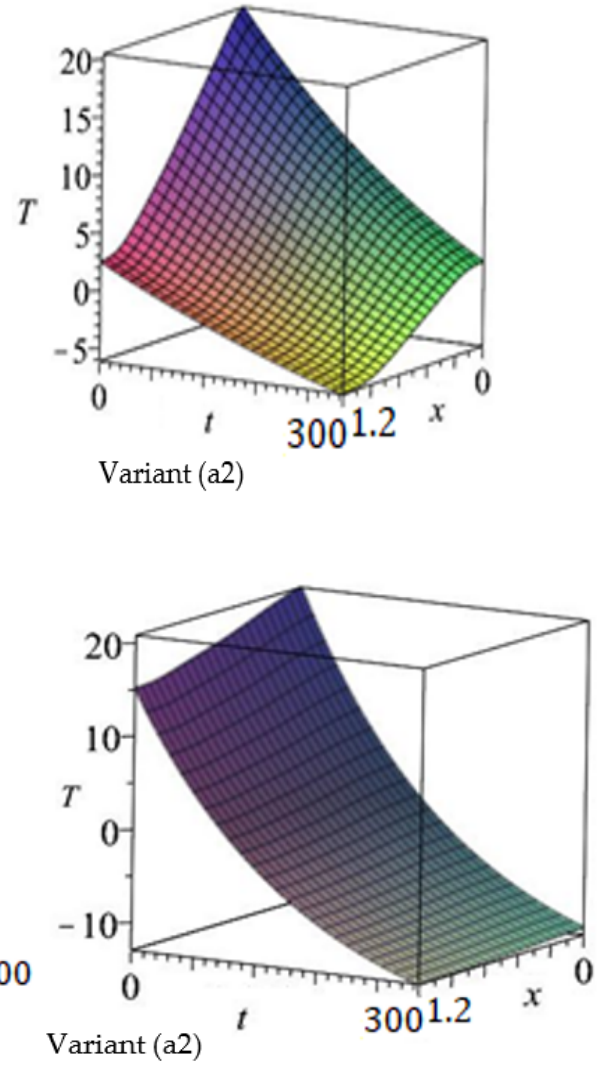

Variant (a1)

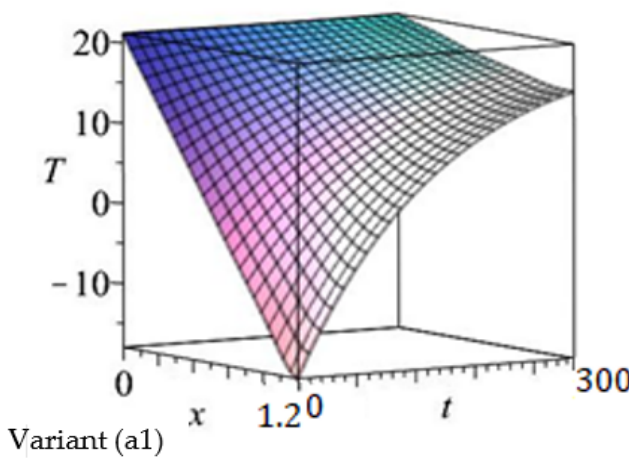

Figure 3. Temperature graphs for the upper surface of a copper plate for $T_{R}=-19{ }^{\circ} \mathrm{C}, v_{a}=0.5 \mathrm{~m} / \mathrm{s}$ (top drawings) and $v_{a}=4.5 \mathrm{~m} / \mathrm{s}$ (bottom drawings) in the case of air exhaust from the room (variant a1) and air supply to the room (variant a2). 
On the left side in Figure 3, one can see the initial temperature for air exhaust from the room changing linearly from $T_{L}=21^{\circ} \mathrm{C}$ to $T_{R}=-19{ }^{\circ} \mathrm{C}$, variant (a1). In the same Figure, above the axis describing time $t$, one can see a change of the right plate end temperature, from $T_{0.5}^{\text {out }}(l, h, 0)=-19{ }^{\circ} \mathrm{C}$ to ca. $T_{0.5}^{\text {out }}\left(l, h, t_{\text {end }}\right)=2.5^{\circ} \mathrm{C}$ for air velocity of $v_{a}=0.5 \mathrm{~m} / \mathrm{s}$ and to ca. $T_{4.5}^{\text {out }}\left(l, h, t_{\text {end }}\right)=15.2^{\circ} \mathrm{C}$, when $v_{a}=4.5 \mathrm{~m} / \mathrm{s}$.

When supplying air from the outside into the room, variant (a2), as seen in the graphs on the right side, it can be seen how an air temperature of $-19{ }^{\circ} \mathrm{C}$ changes, using heat of air exhausting out of the room. At air velocity $v_{a}=0.5 \mathrm{~m} / \mathrm{s}$, the right end of the plate cools down after 5 min from ca. $T_{0.5}^{o u t}\left(l, h, t_{\text {end }}\right)=T_{0.5}^{i n}(l, h, 0)=2.5{ }^{\circ} \mathrm{C}$ to ca. $T_{0.5}^{i n}\left(l, h, t_{\text {end }}\right)=-6.1{ }^{\circ} \mathrm{C}$. At velocity of $v_{a}=4.5 \mathrm{~m} / \mathrm{s}$, this temperature changes from $T_{4.5}^{\text {out }}\left(l, h, t_{\text {end }}\right)=T_{4.5}^{\text {in }}(l, h, 0)=15.2^{\circ} \mathrm{C}$ to $T_{4.5}^{\text {in }}\left(l, h, t_{\text {end }}\right)=-13^{\circ} \mathrm{C}$. In the case of the inlet into the room, with air velocity $v_{a}=0.5 \mathrm{~m} / \mathrm{s}$, the air temperature reaches $T_{0.5}^{i n}\left(0, h, t_{\text {end }}\right)=+1.2{ }^{\circ} \mathrm{C}$ after $5 \mathrm{~min}$. For a velocity $v_{a}=4.5 \mathrm{~m} / \mathrm{s}$, this value is ca. $T_{4.5}^{i n}\left(0, h, t_{\text {end }}\right)=-12.2{ }^{\circ} \mathrm{C}$.

For aluminium and steel and for other values of external temperatures, the temperature distributions are similar to those presented in Figure 3. The temperature values for copper, aluminium, and steel plates are presented in Table 3.

Table 3. The temperatures (in ${ }^{\circ} \mathrm{C}$ ) for $x=0$ and $x=l$ from the room side (superscript 'in'), and from the outside ('out'), for air exhaust from the room and supply to the room, at various outside temperatures and air velocities of $0.5 \mathrm{~m} / \mathrm{s}$ and 4.5 $\mathrm{m} / \mathrm{s}$, in the case of copper, aluminium, and steel plates-comparison. $T_{L}=21^{\circ} \mathrm{C}, t_{\text {end }}=300 \mathrm{~s}$ (time of exhaust $/$ supply). Subscripts indicate $v_{a}$.

\begin{tabular}{|c|c|c|c|c|c|c|c|c|c|c|c|c|c|c|c|c|c|c|}
\hline \multirow[t]{2}{*}{$\begin{array}{c}T_{R} \\
\text { Outside }\end{array}$} & \multicolumn{3}{|c|}{$\begin{array}{c}T_{0.5}^{\text {out }}\left(l, h, t_{\text {end }}\right)= \\
T_{0.5}^{\text {in }}(l, h, 0) \\
\text { Outside }\end{array}$} & \multicolumn{3}{|c|}{$\begin{array}{c}T_{0.5}^{\text {in }}\left(l, h, t_{\text {end }}\right) \\
\text { Outside }\end{array}$} & \multicolumn{3}{|c|}{$\begin{array}{l}T_{0.5}^{i n}\left(0, h, t_{\text {end }}\right) \\
\quad \text { Inside }\end{array}$} & \multicolumn{3}{|c|}{$\begin{array}{c}T_{4.5}^{\text {out }}\left(l, h, t_{\text {end }}\right) \\
=T_{4.5}^{\text {in }}(l, h, 0) \\
\text { Outside }\end{array}$} & \multicolumn{3}{|c|}{$\begin{array}{c}T_{4.5}^{i n}\left(l, h, t_{\text {end }}\right) \\
\text { Outside }\end{array}$} & \multicolumn{3}{|c|}{$\begin{array}{l}T_{4.5}^{i n}\left(0, h, t_{\text {end }}\right) \\
\text { Inside }\end{array}$} \\
\hline & $\mathrm{Cu}$ & Al & Steel & & & Steel & $\mathrm{Cu}$ & & Steel & $\mathrm{Cu}$ & Al & Steel & $\Omega_{0}$ & 1 & Steel & $\mathrm{Cu}$ & Al & Steel \\
\hline$x 19$ & 2.5 & 6 & & -6.1 & -7.6 & -9.2 & 1.2 & -2.5 & 6. & 15.2 & 18 & 10.0 & -10 & & & -12.2 & 5.5 & -8 \\
\hline 1 & 11.8 & 10. & 0.0 & $1 . \pm$ & 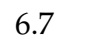 & 0.3 & 11.1 & 9.3 & 13.6 & 18.1 & 13 & 10.0 & 4 & 2.0 & 4.9 & 4.4 & 2.7 & 6.3 \\
\hline 31 & 25.6 & 24.7 & 27.2 & 27.8 & 28.1 & 28.5 & 25.8 & 26.9 & 24.7 & 22.5 & 21.7 & 23.4 & 29.5 & 30.2 & 29.1 & 29.3 & 30.1 & 28.3 \\
\hline
\end{tabular}

The analysis of data in Table 3 indicates that the best plate material is steel, and the air velocity should be around $0.5 \mathrm{~m} / \mathrm{s}$, since in the case of such heat transfer combination, the supplied air temperature in high frosts is not too low, and in the case of high positive temperatures, it does not significantly deviate from room temperature. This is indicated by the values in column $T_{0.5}^{\text {in }}\left(0, h, t_{\text {end }}\right)$ (inside) showing that the temperature of the air supplied to the room is relatively highest in frosty winter and lowest in hot summer.

Copper plates give slightly higher temperature values than aluminium plates. However, copper is more expensive than aluminium or steel (steel is USD 1.84/lb, aluminium is USD $2.87 / \mathrm{lb}$, while copper is USD $4.27 / \mathrm{lb},[31,32]$ ) and is therefore omitted in further discussion concerning the exhaust-supply heat exchanger.

\subsection{Results for Variant (b)}

For the temperature calculation in variants (b), the objective functional $J^{b}$ was used (cf. Equation (23)). The temperature graphs, when air from the room flows above a plate, and the air into the room flows under the plate are shown and discussed below, again, for copper, aluminium, and steel. Plate surface temperature, $y= \pm h$, was studied for $x \in(0, l)$ and $t \in\left(0, t_{\text {end }}\right)$. Figure 4 shows an example of the temperature distribution in the plate as a function of time. Since the plate thickness is very small compared to its length, for $y=+h$ and $y=-h$, its temperature turns out to be virtually the same. As before, the copper plate was considered first. 
for $T_{R}=-19^{\circ} \mathrm{C}$ and $v_{a}=0.5$

for $T_{R}=-19^{\circ} \mathrm{C}$ and $v_{a}=4.5$
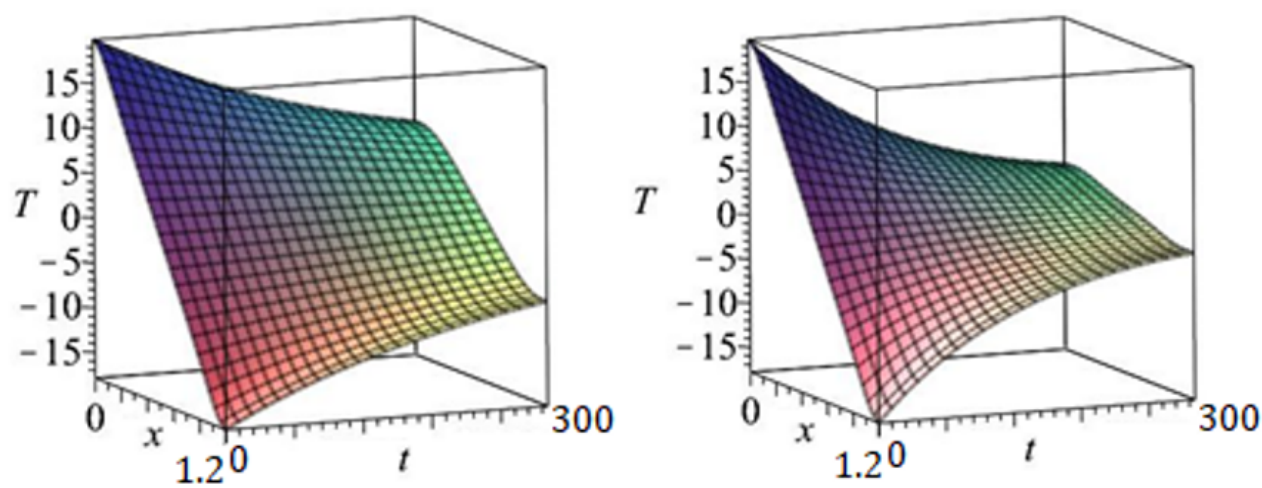

Figure 4. Copper plate temperature graph for $T_{L}=21{ }^{\circ} \mathrm{C}, T_{R}=-19^{\circ} \mathrm{C}$ and two air flow velocities, $v_{a}=0.5 \mathrm{~m} / \mathrm{s}$ and $v_{a}=4.5 \mathrm{~m} / \mathrm{s}$, in the case of air exhaust above the plate and air supply under the plate.

The temperature distributions for aluminium and steel and for other values of external temperatures are similar to those presented in Figure 4. Table 4 focuses on the temperatures for $t_{\text {end }}$, since they are lowest in the frosty winter (highest in the hot summer) throughout the entire process of supplying air into the room.

Table 4. The temperatures (in ${ }^{\circ} \mathrm{C}$ ) of the air for $x=0$ and $x=l$ for a counter-flow heat exchanger, depending on the material, ${ }^{\circ} \mathrm{C}$, two air velocities and various outside temperatures. Supply/exhaust time $t_{\text {end }}=300 \mathrm{~s}, l=1.2 \mathrm{~m}$.

\begin{tabular}{|c|c|c|c|c|c|c|c|c|c|c|c|c|}
\hline \multirow{4}{*}{$\begin{array}{c}T_{R}{ }^{\circ} \mathrm{C} \\
\mathrm{m} / \mathrm{s}\end{array}$} & \multicolumn{6}{|c|}{$\begin{array}{c}T\left(0, h, t_{\text {end }}\right),{ }^{\circ} \mathrm{C} \\
\text { Supply }\end{array}$} & \multicolumn{6}{|c|}{$\begin{array}{c}T\left(l, h, t_{\text {end }}\right),{ }^{\circ} \mathrm{C} \\
\text { Exhaust }\end{array}$} \\
\hline & \multicolumn{2}{|c|}{$\mathrm{Cu}$} & \multicolumn{2}{|c|}{ Al } & \multicolumn{2}{|c|}{ Steel } & \multicolumn{2}{|c|}{$\mathrm{Cu}$} & \multicolumn{2}{|c|}{ Al } & \multicolumn{2}{|c|}{ Steel } \\
\hline & $v_{a}$ & $v_{a}$ & $v_{a}$ & $v_{a}$ & $v_{a}$ & $v_{a}$ & $v_{a}$ & $v_{a}$ & $v_{a}$ & $v_{a}$ & $v_{a}$ & $v_{a}$ \\
\hline & 0.5 & 4.5 & 0.5 & 4.5 & 0.5 & 4.5 & 0.5 & 4.5 & 0.5 & 4.5 & 0.5 & 4.5 \\
\hline-19 & 8.2 & 3.2 & 7.1 & 2.2 & 13 & 6.1 & -6.2 & -1.2 & -5.1 & -0.2 & -11 & -4 \\
\hline 1 & 14.6 & 12.1 & 14 & 11.6 & 17 & 13.5 & 7.4 & 9.9 & 8 & 10.4 & 5 & 8.5 \\
\hline 31 & 24.2 & 25.4 & 24.5 & 25.7 & 23 & 24.7 & 27.8 & 26.6 & 27.5 & 26.3 & 29 & 27.3 \\
\hline
\end{tabular}

The analysis of data in Table 4 indicates that the best plate material for the counter-flow heat exchanger is also steel, and the air velocity should be around $0.5 \mathrm{~m} / \mathrm{s}$ or slightly higher. It should be noted that in the case of severe frosts and at a supply velocity of $0.5 \mathrm{~m} / \mathrm{s}$, the plate temperature on the air inlet into the room falls from the initial value of 21 to $13{ }^{\circ} \mathrm{C}$ after $300 \mathrm{~s}$, while in the case of high positive temperatures, it increases above $21^{\circ} \mathrm{C}$ but does not exceed $23{ }^{\circ} \mathrm{C}$.

Again, copper plates give slightly higher temperature values than aluminium plates. However, for the reasons mentioned above, for counter-flow heat exchangers, copper plates are also omitted in the further discussion.

\section{Discussion}

The analysis of the results presented in Section 4 shows that the use of a counter-flow exchanger is a better method of air exchange, and the best material of the heat exchanger plates is steel. This is illustrated in Table 5. In the case of a counter-flow heat exchanger, the temperature of the air supplied into the room is relatively highest when it is cold outside and lowest when it is hot. 
Table 5. Comparison of temperatures for $x=0$ and $x=l$ after $t_{\text {end }}=300 \mathrm{~s}$, for a steel-plate recuperator, operating in the exhaust-supply mode and for a counter-flow heat exchanger.

\begin{tabular}{|c|c|c|c|c|c|c|c|c|}
\hline \multirow{3}{*}{$\begin{array}{c}T_{R},{ }^{\circ} \mathrm{C} \\
v_{a}, \mathrm{~m} / \mathrm{s}\end{array}$} & \multicolumn{4}{|c|}{$\begin{array}{c}T\left(0, h, t_{\text {end }}\right),{ }^{\circ} \mathrm{C} \\
\text { Supply }\end{array}$} & \multicolumn{4}{|c|}{$\begin{array}{c}T\left(l, h, t_{\text {end }}\right),{ }^{\circ} \mathrm{C} \\
\text { Exhaust }\end{array}$} \\
\hline & \multicolumn{2}{|c|}{ Exhaust-Supply } & \multicolumn{2}{|c|}{ Counter-Flow } & \multicolumn{2}{|c|}{ Exhaust-Supply } & \multicolumn{2}{|c|}{ Counter-Flow } \\
\hline & 0.5 & 4.5 & 0.5 & 4.5 & 0.5 & 4.5 & 0.5 & 4.5 \\
\hline-19 & 6.2 & -8.4 & 13 & 6.1 & -9.2 & -11.3 & -11 & -4 \\
\hline 1 & 13.6 & 6.3 & 17 & 13.5 & 5.9 & 4.9 & 5 & 8.5 \\
\hline 31 & 24.7 & 28.3 & 23 & 24.7 & 28.5 & 29.1 & 29 & 27.3 \\
\hline
\end{tabular}

The analysis in Section 4 was applied to a situation when air transfer inside the room lasted 300 (exhaust) +300 (supply) seconds or with a counter-flow process lasting $300 \mathrm{~s}$. Tables $6-8$ show the supply and exhaust temperatures $t_{\text {end }}$ in exchangers made of $0.8 \mathrm{~m}, 1.0 \mathrm{~m}$, and $1.2 \mathrm{~m}$ long plates, after a heat transfer time of 300,600, and $900 \mathrm{~s}$, in the counter-flow mode.

Table 6. Temperatures for $x=0$ and $x=l$ on the air outlet from the room and fresh air inlet into the room for a counter-flow heat exchanger made from steel plates, ${ }^{\circ} \mathrm{C}$, various air exchange durations, two air velocities, different outside temperatures, and plate lengths $l=0.8 \mathrm{~m}$.

\begin{tabular}{|c|c|c|c|c|c|c|c|c|c|c|c|c|}
\hline \multirow{2}{*}{$T_{R}{ }^{\circ} \mathrm{C}$} & \multicolumn{6}{|c|}{$\begin{array}{c}T\left(0, h, t_{\text {end }}\right),{ }^{\circ} \mathrm{C} \\
\text { Supply }\end{array}$} & \multicolumn{6}{|c|}{$\begin{array}{c}T\left(l, h, t_{\text {end }}\right),{ }^{\circ} \mathrm{C} \\
\text { Exhaust }\end{array}$} \\
\hline & \multicolumn{2}{|c|}{$300 \mathrm{~s}$} & \multicolumn{2}{|c|}{$600 \mathrm{~s}$} & \multicolumn{2}{|c|}{$900 \mathrm{~s}$} & \multicolumn{2}{|c|}{$300 \mathrm{~s}$} & \multicolumn{2}{|c|}{$600 \mathrm{~s}$} & \multicolumn{2}{|c|}{$900 \mathrm{~s}$} \\
\hline \multirow{2}{*}{$\mathrm{m} / \mathrm{s}$} & $v_{a}$ & $v_{a}$ & $v_{a}$ & $v_{a}$ & $v_{a}$ & $v_{a}$ & $v_{a}$ & $v_{a}$ & $v_{a}$ & $v_{a}$ & $v_{a}$ & $v_{a}$ \\
\hline & 0.5 & 4.5 & 0.5 & 4.5 & 0.5 & 4.5 & 0.5 & 4.5 & 0.5 & 4.5 & 0.5 & 4.5 \\
\hline-19 & 12.6 & 5.9 & 8.1 & 2.3 & 5.4 & 1.4 & -10.6 & -3.8 & -6.1 & -0.3 & -3.4 & 0.6 \\
\hline 1 & 16.8 & 13.4 & 14.6 & 11.7 & 13.2 & 11.2 & 5.2 & 8.6 & 7.4 & 10.4 & 8.8 & 10.8 \\
\hline 31 & 23.1 & 24.8 & 24.2 & 25.7 & 24.9 & 25.9 & 28.9 & 27.2 & 27.8 & 26.3 & 27.1 & 26.1 \\
\hline
\end{tabular}

Table 7. Temperatures for $x=0$ and $x=l$ on the air outlet from the room and fresh air inlet into the room for a counter-flow heat exchanger made from steel plates, ${ }^{\circ} \mathrm{C}$, various air exchange durations, two air velocities, different outside temperatures, and plate lengths $l=1 \mathrm{~m}$.

\begin{tabular}{|c|c|c|c|c|c|c|c|c|c|c|c|c|}
\hline \multirow{4}{*}{$\frac{T_{R}{ }^{\circ} \mathrm{C}}{\mathrm{m} / \mathrm{s}}$} & \multicolumn{6}{|c|}{$\begin{array}{c}T\left(0, h, t_{\text {end }}\right),{ }^{\circ} \mathrm{C} \\
\text { Supply }\end{array}$} & \multicolumn{6}{|c|}{$\begin{array}{c}T\left(l, h, t_{\text {end }}\right),{ }^{\circ} \mathrm{C} \\
\text { Exhaust }\end{array}$} \\
\hline & \multicolumn{2}{|c|}{$300 \mathrm{~s}$} & \multicolumn{2}{|c|}{$600 \mathrm{~s}$} & \multicolumn{2}{|c|}{$900 \mathrm{~s}$} & \multicolumn{2}{|c|}{$300 \mathrm{~s}$} & \multicolumn{2}{|c|}{$600 \mathrm{~s}$} & \multicolumn{2}{|c|}{$900 \mathrm{~s}$} \\
\hline & $v_{a}$ & $v_{a}$ & $v_{a}$ & $v_{a}$ & $v_{a}$ & $v_{a}$ & $v_{a}$ & $v_{a}$ & $v_{a}$ & $v_{a}$ & $v_{a}$ & $v_{a}$ \\
\hline & 0.5 & 4.5 & 0.5 & 4.5 & 0.5 & 4.5 & 0.5 & 4.5 & 0.5 & 4.5 & 0.5 & 4.5 \\
\hline-19 & 12.9 & 6 & 8.6 & 2.4 & 5.7 & 1.5 & -10.9 & -3.9 & -6.4 & -0.3 & -3.6 & 0.6 \\
\hline 1 & 16.9 & 13.5 & 14.7 & 11.7 & 13.3 & 11.2 & 5.1 & 8.5 & 7.3 & 10.3 & 8.7 & 10.8 \\
\hline 31 & 23 & 24.8 & 24.1 & 25.7 & 24.8 & 25.9 & 29 & 27.2 & 27.8 & 26.3 & 27.2 & 26.1 \\
\hline
\end{tabular}


Table 8. Temperatures for $x=0$ and $x=l$ on the air outlet from the room and fresh air inlet into the room for a counter-flow heat exchanger made from steel plates, ${ }^{\circ} \mathrm{C}$, various air exchange durations, two air velocities, different outside temperatures, and plate lengths $l=1.2 \mathrm{~m}$.

\begin{tabular}{|c|c|c|c|c|c|c|c|c|c|c|c|c|}
\hline \multirow{4}{*}{$\begin{array}{c}T_{R}{ }^{\circ} \mathrm{C} \\
\mathrm{m} / \mathrm{s}\end{array}$} & \multicolumn{6}{|c|}{$\begin{array}{c}T\left(0, h, t_{\text {end }}\right),{ }^{\circ} \mathrm{C} \\
\text { Supply }\end{array}$} & \multicolumn{6}{|c|}{$\begin{array}{c}T\left(l, h, t_{\text {end }}\right),{ }^{\circ} \mathrm{C} \\
\text { Exhaust }\end{array}$} \\
\hline & \multicolumn{2}{|c|}{$300 \mathrm{~s}$} & \multicolumn{2}{|c|}{$600 \mathrm{~s}$} & \multicolumn{2}{|c|}{$900 \mathrm{~s}$} & \multicolumn{2}{|c|}{$300 \mathrm{~s}$} & \multicolumn{2}{|c|}{$600 \mathrm{~s}$} & \multicolumn{2}{|c|}{$900 \mathrm{~s}$} \\
\hline & $v_{a}$ & $v_{a}$ & $v_{a}$ & $v_{a}$ & $v_{a}$ & $v_{a}$ & $v_{a}$ & $v_{a}$ & $v_{a}$ & $v_{a}$ & $v_{a}$ & $v_{a}$ \\
\hline & 0.5 & 4.5 & 0.5 & 4.5 & 0.5 & 4.5 & 0.5 & 4.5 & 0.5 & 4.5 & 0.5 & 4.5 \\
\hline-19 & 13 & 6.1 & 8.6 & 2.5 & 5.8 & 1.5 & -11 & -4 & -6.6 & -0.4 & -3.8 & 0.6 \\
\hline 1 & 17 & 13.5 & 14.8 & 11.7 & 13.4 & 11.2 & 5 & 8.5 & 7.2 & 10.3 & 8.6 & 10.8 \\
\hline 31 & 23 & 24.7 & 24.1 & 25.6 & 24.8 & 25.9 & 29 & 27.3 & 27.9 & 26.3 & 27.2 & 26.1 \\
\hline
\end{tabular}

As indicated by the data from Table 6 , when the exchanger operation time is $300 \mathrm{~s}$, with plates $0.8 \mathrm{~m}$ long and air velocity $0.5 \mathrm{~m} / \mathrm{s}$, the temperature difference between air supply in frost conditions and hot weather is about 10.5 degrees, with the outside temperature difference reaching 50 degrees. When high heat transfer velocity $(4.5 \mathrm{~m} / \mathrm{s})$ takes place, this difference is almost twice as high (ca. 19 degrees).

A longer operation time of the counter-flow plate heat exchanger, at the air velocity of $0.5 \mathrm{~m} / \mathrm{s}$, lowers the supply air temperature for $x=0$ in severe frosts even to $8.1{ }^{\circ} \mathrm{C}$ after $600 \mathrm{~s}$ and to $5.4{ }^{\circ} \mathrm{C}$ after $900 \mathrm{~s}$. In the case of high supply velocity of $4.5 \mathrm{~m} / \mathrm{s}$, the final supply temperatures are significantly lower than for a supply velocity of $0.5 \mathrm{~m} / \mathrm{s}$. In addition, the equalization of the supply and exhaust temperature over time on both plate ends is visible.

This indicates that exchangers with $0.8 \mathrm{~m}$ long plates should be used at low air flow velocities.

Table 7 indicates that the extension of exchanger plates from 0.8 to $1.0 \mathrm{~m}$ slightly increases the supply temperatures in severe frosts. A longer heat exchanger operation time leads to a reduced difference between supply and exhaust temperatures, just like for an exchanger that is $0.8 \mathrm{~m}$ long.

Table 8 shows that further extension of exchanger plates improves temperature but only slightly. It follows that the best exchanger plate length is $1 \mathrm{~m}$.

As mentioned in the Introduction, exchangers are built mainly of the weather-resistant aluminium. However, the presented computations indicate that steel would be a material better in terms of heat dissipation when supplying fresh air into a room. It is obvious that a steel plate can be much thinner than that adopted for the purposes of this paper. The presented research shows that the thinner the plate, the less the supply air heats up, although the differences are slight. The differences in the final air temperatures are greater only in severe frosts, as presented in Table 9.

Table 9. Comparison of temperatures on the fresh air inlet to a room, $T\left(0, h, t_{\text {end }}\right)$, for various outside temperatures and a counter-flow heat exchanger made of $1.2 \mathrm{~mm}$ thick aluminium plates and of steel plates of various thickness for an air exchange duration $t_{\text {end }}=$ of $300 \mathrm{~s}$ and air velocities $v_{a}=0.5 \mathrm{~m} / \mathrm{s}$ and $v_{a}=4.5 \mathrm{~m} / \mathrm{s}$.

\begin{tabular}{ccccccccc}
\hline \multirow{2}{*}{$\boldsymbol{T}_{\boldsymbol{R}},{ }^{\circ} \mathbf{C}$} & \multicolumn{8}{c}{$\mathbf{T}\left(0, \mathbf{h}, t_{\text {end }}\right),{ }^{\circ} \mathbf{C}$} \\
\cline { 2 - 10 } & & Al & \multicolumn{7}{c}{ Steel, $\mathbf{h}=\mathbf{1 . 2} \mathbf{~ m m}$} & Steel, $\mathbf{h}=\mathbf{0 . 8} \mathbf{~ m m}$ & \multicolumn{2}{c}{ Steel, $\mathbf{h}=\mathbf{0 . 4} \mathbf{~ m m}$} \\
\hline$v_{a}, \mathrm{~m} / \mathrm{s}$ & 0.5 & 4.5 & 0.5 & 4.5 & 0.5 & 4.5 & 0.5 & 4.5 \\
\hline-19 & 7.1 & 2.2 & 13 & 6.1 & 6.1 & 1.5 & 2.5 & -0.5 \\
\hline 1 & 14 & 11.6 & 17 & 13.5 & 13.5 & 11.3 & 11.7 & 10.3 \\
\hline 31 & 24.5 & 25.7 & 23 & 24.7 & 24.7 & 25.9 & 25.6 & 26.4 \\
\hline
\end{tabular}


As can be seen in Table 9, the final air inlet temperature $T\left(0, h, t_{\text {end }}\right)$, at approximately $1{ }^{\circ} \mathrm{C}$, is lower by ca. $0.5^{\circ} \mathrm{C}$ for $0.8 \mathrm{~mm}$ thick steel plates than for $150 \%$ thicker aluminium plates; however, in the case of air supply during a hot summer day, this difference is only $0.2{ }^{\circ} \mathrm{C}$. Only during a harsh winter, the difference in the final temperatures is ca. $2{ }^{\circ} \mathrm{C}$. Therefore, a heat exchanger with $0.8 \mathrm{~mm}$ thick steel plates will exhibit similar performance to a heat exchanger with aluminium plates. It should be noted that it is much cheaper, although it is a little heavier. For steel plates ca $0.4 \mathrm{~mm}$ thick, the final air inlet temperatures are less favourable than for aluminium plates that are $1.2 \mathrm{~mm}$ thick (almost $5^{\circ} \mathrm{C}$ for a harsh winter, more than $2{ }^{\circ} \mathrm{C}$ for the spring-autumn period, and approximately $1^{\circ} \mathrm{C}$ for a hot summer). However, at the same time, the weight of a heat exchanger made of $0.4 \mathrm{~mm}$ thick steel plates is a bit lower than the weight of that made of aluminium plates, and with the exchanger operation time less than $300 \mathrm{~s}$, the final air inlet temperatures will be similar to the temperatures achieved in an aluminium-plate exchanger.

It should be noted that the temperatures achieved for steel plates with a thickness of $0.4 \mathrm{~mm}$ and $0.8 \mathrm{~mm}$, and a supply velocity of $0.5 \mathrm{~m} / \mathrm{s}$ are very similar to temperatures at a supply velocity of $4.5 \mathrm{~m} / \mathrm{s}$ but for plates that are thicker by $0.4 \mathrm{~mm}$.

As mentioned in the Introduction, exchangers are mainly made of the weatherresistant aluminium. However, the presented computations indicate that steel would be a better material in terms of heat dissipation when supplying fresh air into a room.

Consider the temperature transfer efficiency of aluminium and steel exhaust/supply and counter-flow heat exchangers. The efficiency is calculated from the formula, [33],

$$
\eta_{T}=\frac{T_{i n}-T_{R}}{T_{L}-T_{R}}
$$

where $T_{\text {in }}$ stands for supply air temperature, and $T_{R}$ and $T_{L}$ are outside and room temperature, respectively. The average of $T_{L}$ and $T\left(0, h, t_{\text {end }}\right)$ for $v_{a}=0.5 \mathrm{~m} / \mathrm{s}$ is taken as $T_{\text {in }}$ (see Table 3 for exhaust/supply and Table 4 for counter-flow exchangers). When comparing the temperature transfer efficiency for the considered heat exchangers, its value is calculated for $T_{R}=1{ }^{\circ} \mathrm{C}$ and $T_{L}=21{ }^{\circ} \mathrm{C}$. For the counter-flow exchanger, we get $\eta_{T, A l}=0.825$, $\eta_{T, \text { steel }}=0.9$, and for the exhaust/supply, $\eta_{T, A l}=0.7075, \eta_{T, \text { steel }}=0.815$. The advantage of the counter-flow heat exchanger over the exhaust-supply heat exchanger and steel over aluminium is evident. In addition, steel is cheaper than aluminium (steel is USD 1.84/lb, aluminium is USD $2.87 / \mathrm{lb}$ ). However, steel plate heat exchangers are heavier. The use of thinner steel plates can reduce the weight.

\section{Conclusions}

The Trefftz functions have been adopted as the baseline for the approximate solution of the problem. As shown in Table 1, it is sufficient to use the first several dozen T-functions in order to achieve an approximate solution that describes the temperature field in the exchanger plate with adequate accuracy, approximating the fulfilment of the boundary conditions by means of the least squares method.

As could be expected, the plate thickness $(1.2 \mathrm{~mm})$ in relation to the length means that although the equation has been solved for $x, y, t$ (dimensionless $\xi, \eta, \tau$ ), the results practically depend only on $x$ and $t$. It follows that the plate section of the heat exchanger can be considered one-dimensional.

The results clearly show how temperature distribution depends on air velocity. It is obvious that lower air velocities are more favourable in terms of recovering heat from the supplied heat that is transferred with the air during extraction. In numerical terms, this is described in Tables 3-8.

The presented analysis indicates that counter-flow exchangers are more effective than those operating in the exhaust-supply mode. If we consider plates that are $0.8 \mathrm{~m}, 1.0 \mathrm{~m}$, and $1.2 \mathrm{~m}$ long, their length is of secondary significance; it seems that the best results in relation to the potential production costs are obtained for the length $l=1.0 \mathrm{~m}$. The 
comparison of the three considered materials for the heat exchanger plates shows that steel is the best.

The exchanger operation time is significant to the temperature of air supplied to the room. In the case of cold periods, this time should be shorter. In the case of positive temperatures, the exchanger operation time can be longer, and the computation results indicate that $300 \mathrm{~s}$ is the best option.

Air humidity and pollution are not included in the analysis. However, the results obtained with the simplifications applied are in line with the practice of designing and using heat exchangers/recuperators.

Author Contributions: Conceptualization, K.G., A.M. and A.Ś; methodology, K.G. and A.M.; software, A.M.; validation, K.G., A.M. and A.S.; formal analysis, K.G. and A.M.; investigation, K.G. and A.M.; resources, K.G., A.M. and A.Ś.; data curation, K.G., A.M. and A.Ś.; writing-original draft preparation, K.G.; writing-review and editing, K.G. and A.M.; visualization, K.G. and A.M.; supervision, K.G. and A.M.; project administration, K.G.; funding acquisition, K.G. and A.M. All authors have read and agreed to the published version of the manuscript.

Funding: Kielce University of Technology.

Institutional Review Board Statement: Not applicable.

Informed Consent Statement: Not applicable.

Data Availability Statement: Not applicable.

Conflicts of Interest: The authors declare no conflict of interest.

\section{References}

1. Shah, R.K.; Sekulic, D.P. 2003, Classification of Heat Exchangers. In Fundamentals of Heat Exchanger Design; John Wiley and Sons: Hoboken, NJ, USA, 2007; Chapter 1; pp. 1-77.

2. Wang, L.; Sundén, B.; Manglik, R.M. Plate Heat Exchangers, Design, Applications and Performance; WIT Press: Southampton, Boston, MA, USA, 2007.

3. Recuperators. Available online: https://www.rekuperatory.pl/rekuperator\#co-to-jest-rekuperator (accessed on 30 June 2021).

4. Xu, K. Design and Optimization of Plate Heat Exchanger Networks. Ph.D. Thesis, The University of Manchester, Faculty of Science and Engineering, Manchester, UK, 2019.

5. Tsai, Y.C.; Liu, F.B.; Shen, P.T. Investigation of effect of oblique ridges on heat transfer in plate heat exchangers. Int. Comm Heat Mass Transf. 2009, 36, 574-578. [CrossRef]

6. Liu, F.B.; Tsai, Y.C. An experimental and numerical investigation of fluid flow in a cross-corrugated channel. Heat Mass Transf. 2010, 46, 585-593. [CrossRef]

7. Gherasim, I.; Galanis, N.; Nguyen, C.T. Heat transfer and fluid flow in a plate heat exchanger. Part II: Assessment of laminar and two-equation turbulent models. Int. J. Therm. Sci. 2011, 50, 1499-1511. [CrossRef]

8. Novosád, J.; Dvořák, V. Investigation of effect of oblique ridges on heat transfer in plate heat exchangers. In Experimental Fluid Mechanics 2013, Vit, T., Dančová, P., Novotný, P., Eds.; EDP Sciences: Les Ulis, France, 2013; pp. 510-514. [CrossRef]

9. Borhani, M.; Yaghoubi, S. Numerical simulation of heat transfer in a parallel plate channel and promote dissipative particle dynamics method using different weight functions. Int. Commun. Heat Mass Transf. 2020, 115, 104606. [CrossRef]

10. Jamshak, S.H.; Dev Anand, M.; Akshay, S.B.; Arun, S.; Prajeev, J.; Prabhakaran, P. Design and Analysis of a Plate Heat Exchanger in the View of Performance Improvement and Cost Reduction. Int. J. Engngy Technol. 2018, 7, 440-446. [CrossRef]

11. Reynolds, B.W. Simulation of Flow and Heat Transfer in 3D Printable Triply Periodic Minimal Surface Heat Exchangers. Ph.D. Thesis, University of Canterbury, Christchurch, New Zealand, August 2020.

12. Jahn, I.H.J. Code for the Design and Evaluation of Heat Exchangers for Complex Fluids; Mechanical Engineering Technical Report 2017/04; School of Mechanical and Mining Engineering, The University of Queensland: Queensland, Austrilia, 2017.

13. Huang, S.M.; Qiu, D.; Ye, W.B.; Hong, Y.; Huang, W.; Yang, M. Effects of the Random Distributions on the Laminar Flow and Heat Transfer in a Quasi-Counter Flow Parallel-Plate Membrane Channel. Heat Transf. Eng. 2018, 39, 17-18, 1520-1527. [CrossRef]

14. Bai, H.; Zhu, J.; Chen, Z.; Chu, J. Parametric analysis of a cross-flow membrane-based parallel-plate liquid desiccant dehumidification system: Numerical and experimental data. Energy Build. 2018, 158, 494-508. [CrossRef]

15. Dvořák, V.; Vít, T. Numerical investigation of counter flow plate heat exchanger. In Proceedings of the 7th International Conference on Sustainability in Energy and Buildings, Madeira, Portugal, 16-19 May 2017. Energy Procedia 2015, 83, 341-349. [CrossRef]

16. Dvořák, V.; Vít, T. CAE methods for plate heat exchanger design. In Proceedings of the 9th International Conference on Sustainability in Energy and Buildings, SEB-17, Chania, Crete, Greece, 5-7 July 2017. Procedia Eng. 2017, 134, 234-243. [CrossRef] 
17. de Schampheleire, S.; de Kerpel, K.; Ameel, B.; Huisseune, H.; de Paepe, M. Thermal Analysis of a Commercial Plate Fin Heat Exchanger With Nonuniform Inlet Flow Conditions. Heat Transf. Eng. 2016, 37, 1466-1477. [CrossRef]

18. Carslaw, H.S.; Jaeger, J.C. Conduction of Heat in Solids; Oxford University: Oxford, UK, 1959.

19. Mills, A.F. Basic Heat and Mass Transfer; Prentice-Hall: Upper Saddle River, NJ, USA, 1999.

20. Available online: https://www.engineersedge.com/thermodynamics/overall_heat_transfer-table.htm (accessed on 9 September 2021).

21. Inhelder, J. Verbrauchs und Schadstoffoptimiertes Ottomotor-Aufladekonzept. Ph.D. Thesis, Swiss Federal Institute of Technology, Zürich, Switzerland, 1996. Diss. ETH No. 11948.

22. Eriksson, L.; Nielsen, L. Modeling and Control of Engines and Drivelines; Wiley: New York, NY, USA, 2014 ; App. A; p. 530.

23. Sforza, P. Commercial Airplane Design Principles; Elsevier Inc.: Amsterdam, The Netherlands, 2014; ISBN 978-0-12-419953-8.

24. White, F. Fluid Mechanics, 4th ed.; McGraw-Hill Higher Education: New York, NY, USA, 2002; ISBN 0-07-228192-8.

25. Incropera, F.P.; DeWitt, D.P. Fundamentals of Heat Transfer; Wiley: New York, NY, USA, 1981; ISBN 978-0-471-42711-7.

26. Trefftz, E. Ein Gegenstueck zum Ritz'schen Verfahren. In Proceedings of the 2nd International Congress of Applied Mechanics, Zurich, Switzerland, 12-17 September 1926; pp. 131-137.

27. Grysa, K.; Maciejewska, B. Trefftz functions for non-stationary problems. J. Theoret. Appl. Mech. 2013, 50, $251-264$.

28. Ciałkowski, M.J.; Frackowiak, A. Thermal and related functions used in solving certain problems of mechanics, Part I. Solving some differential equations with the use of inverse operator. In Modern Problems of Technics; University of Zielona Góra Publishers: Zielona Góra, Poland, 2003; Volume 3, pp. 7-70.

29. Maciag, A.; Grysa, K. Trefftz Method of Solving a 1D Coupled Thermoelasticity Problem for One- and Two-Layered Media. Energies 2021, 14, 3637. [CrossRef]

30. Doniec, A. Data set for chemical engineering calculations. In Seria: Skrypty dla Szkót Wyższych; Technical University of Lodz: Lodz, Poland, 1981. (In Polish)

31. Prices of Metals. Available online: https://agmetalminer.com/metal-prices/ (accessed on 8 December 2021).

32. Copper Prices: Check Live \& Historical Copper Spot Prices. Available online: https://www.moneymetals.com/copper-prices (accessed on 8 December 2021).

33. Heat Recovery Efficiency. Available online: https://www.engineeringtoolbox.com/heat-recovery-efficiency-d_201.html (accessed on 8 December 2021). 